\title{
Los sucesos de nuestros días
}

\section{The events of our days}

\author{
Andres José Dulcey-Cepeda ${ }^{1}$
}

Reflexionar es una tarea compleja, especialmente en nuestro país que, habitualmente inestable, violento y turbulento, vive unas de sus horas más oscuras. En Colombia nos enfrentamos ahora a dos dramáticos desafíos. En primer lugar, las consecuencias terribles de la pandemia del COVID-19 con 81.310 fallecidos y más de 3 millones de casos reportados oficialmente hasta hoy, 16 de mayo de 2021. Encontramos un país al borde del colapso hospitalario, con sus sistemas de salud pública debilitados, con los equipos de salud cansados y con escasez de insumos.

Nuestro gremio ha enfrentado con singular valentía y estoicismo esta tarea monumental, aportando un número muy significativo entre los contagiados y fallecidos. En mi caso personal puedo afirmar, como la mayoría de los médicos de nuestro país, que entre sus conocidos ya es excepcional aquel que no se ha infectado por coronavirus y debo agregar, con profundo dolor, como entre esos fallecidos hay colegas, maestros y amigos entrańables.

Cuando conviene nos llaman "héroes", pero seguimos siendo un sector cada vez más precarizado, con condiciones laborales deteriorándose progresivamente. Al hecho

\section{Historial del artículo}

Fecha de recepción: 15/04/2021

Fecha de aprobación: 25/05/2021

1 Universidad del Cauca, Profesor de la Facultad de Ciencias de la Salud, Médico especialista en Psiquiatría. Popayán, Colombia.

Correspondencia: Andrés José Dulcey-Cepeda. Universidad del Cauca, Carrera 5 \# 13N - 36 Popayán, Colombia. Correo Electrónico: adulcey@unicauca.edu.co

Como citar este artículo: Dulcey-Cepeda AJ. Los sucesos de nuestros días. Revista de la Facultad de Ciencias de la Salud de la Universidad del Cauca. 2021;23(1):47-48. https://doi.org/10.47373/rfcs.2021.v23.1952 
de habernos convertido en mano de obra barata y muy cualificada, en una industria que enriquece a cualquiera menos al trabajador de la salud, se suma el hecho que nuestras voces en medio de este escenario dantesco no han sido escuchadas. Una vez se hizo clara la llegada del tercer pico de la pandemia de coronavirus, las diferentes asociaciones médicas y científicas colombianas clamaron al cielo por decretar cuarentenas estrictas en Atlántico, Antioquia y Bogotá. Estos clamores fueron olímpicamente ignorados por las autoridades en capacidad de tomar estas determinaciones.

Una pandemia, al ser un problema de salud pública, no puede pretender manejarse exclusivamente con el autocuidado. Se entregó al ciudadano la responsabilidad de evitar enfermarse. En estos casos se requiere la presencia de un estado que priorice lo público, pero nuestro estado pretende hace mucho rato ver la salud como un lucrativo negocio para unos pocos y no como un derecho fundamental, así que los juiciosos reclamos por cuarentena no fueron oídos, era necesario producir.

Claro, se consiguieron las vacunas; hasta mayo 13 de 2021 la cifra oficial mencionaba que 2.693.154 personas estábamos completamente inmunizadas, lo cual es solamente un exiguo $5,3 \%$ del total de nuestra población. La vacunación no marcha como debería haber marchado.

El gremio médico igualmente clama por retirar de las discusiones del congreso el proyecto de ley 010 que pretende reformar a la salud. Ese debate no surgió en medio de la efervescencia del actual paro nacional; se viene insistiendo en todos los escenarios, desde hace meses, en que esa reforma tal como está concebida solo agravará las profundas deficiencias de nuestro ya maltrecho sistema de salud.

Oídos sordos de las autoridades políticas de nuestra nación al clamor de sus científicos, de sus médicos; oídos sordos ante el clamor de una población atemorizada, exhausta y empobrecida por los efectos de la pandemia.

Se negaron, como lo han hecho sistemáticamente, a oír a la gente. Las autoridades políticas volvieron a descargar en sus ciudadanos de estratos bajos y medios, la responsabilidad de enfrentar el empobrecimiento del país con una reforma tributaria que no podía haberse planteado en un momento y términos más inoportunos e inadecuados. Esa negativa a escuchar, a entender las necesidades de una población que históricamente no ha pedido mucho (tan poco exigimos que hasta hace muy poco tiempo nos autoproclamábamos "el país más feliz del mundo"), es uno de los factores que explican la génesis del segundo desafío que hoy afrontamos: el estallido social.

En la década de los ańos 60 del siglo pasado, el médico fundador de la escuela de salud pública de la Universidad de Antioquia, el doctor Héctor Abad Gómez, fue duramente cuestionado por el decano de su facultad, quien lo llamó "agitador de masas". El motivo de este seńalamiento era una serie de columnas escritas en la prensa de Medellín por esos días. La respuesta del doctor Abad Gómez al decano decía: "Debo manifestar a usted, muy respetuosamente, que nunca he entendido mi posición profesoral como una renuncia a mis derechos de ciudadano y a la libre expresión de mis ideas y opiniones en la forma que lo crea conveniente... creo que he tenido siempre por mira el bien público, y que siendo la catedra que dirijo esencialmente de servicio general y de contacto con la realidad colombiana, no me podría aislar, ni aislar a mis estudiantes, en una torre académica de marfil, siendo que, al contrario, debería entrar de lleno en contacto con los reales problemas colombianos, no con los futuros y pasados, sino también con los presentes, para que la universidad no siga siendo un ente etéreo, aislado de las angustias de la gente, de espaldas al medio y sostenedora de los viejos métodos y privilegios que han mantenido en la edad media de la injusticia social al pueblo colombiano" (1).

Las palabras de ese médico honesto, bueno y sabio resuenan y cobran actualidad más que nunca. Nuestro deber trasciende las aulas de clase y los pasillos hospitalarios. Tenemos derecho a sentir y disentir. Tenemos derecho a expresar nuestra voz, y tenemos la obligación de conocer la realidad de nuestro pueblo. Aislarse en la torre de marfil, así sea académica, es asumir la misma actitud obcecada que cuestionamos en nuestros dirigentes.

\section{REFERENCIAS}

1. Faciolince Hector Abad. El olvido que seremos. 1ra edición. Bogotá, Colombia. Editorial Planeta Colombiana; 2006. 